\title{
Research Paper: A Five-Year Report on Clinical and Demographic Characteristics of Children and Adolescents Admitted to a Major Psychiatric Hospital
}

\author{
Rosa Alikhani $^{1}$ (D), Mehdi Tehrani-Doost ${ }^{2,3} \mathbb{D}$, Zahra Shahrivar ${ }^{2,3^{*}}$ (D) \\ 1. Department of Psychiatry, Psychosis Research Center, University of Social Welfare and Rehabilitation Sciences, Tehran, Iran \\ 2. Research Center for Cognitive and Behavioral Sciences, Tehran University of Medical Sciences, Tehran, Iran. \\ 3. Roozbeh Psychiatry Hospital, Tehran University of Medical Sciences, Tehran, Iran.
}

\begin{tabular}{|c|c|}
\hline $\begin{array}{l}\text { Use your device to scan } \\
\text { and read the article online }\end{array}$ & \\
\hline 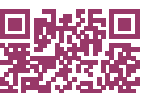 & $\begin{array}{l}\text { Children and Adolescents Admitted to a Major Psychiatric Hospital. Iranian Rehabilitation Journal. 2019; 17(3):253-262. http:// } \\
\text { dx.doi.org/10.32598/irj.17.3.253 }\end{array}$ \\
\hline 口itat & doli http://dx.doi.org/10.32598/irj.17.3.253 \\
\hline
\end{tabular}

Article info:

Received: 25 Oct 2018

Accepted: 10 Apr 2019

Available Online: 01 Sep 2019

Keywords:

Psychiatry, Rehabilitation, Inpatient

\section{ABSTRACT}

Objectives: More attention is now paid on the importance of emotional and mental well-being of the youth. To better plan for psychiatric health care and rehabilitation in this age group, we need to shed light on the epidemiological picture of their mental disorders. The present study aimed to evaluate the demographic and clinical characteristics of the referrals to a child and adolescent psychiatric ward during 5 years.

Methods: In this prospective observational study, all the youth, who had been admitted to the Roozbeh Hospital for the first time, were recruited. All of the participants were evaluated, using the Roozbeh Hospital Item Sheet as a standard tool for obtaining their demographic and clinical features. The level of global functioning was also assessed, utilizing the Children Global Assessment Scale.

Results: Over $55 \%$ of the inpatients $(\mathrm{n}=192)$ were male with a Mean \pm SD age of $15.2 \pm 2.36$ years. The average length of admission was 40 days. The most common diagnoses were (in descending sequences): 1. bipolar mood disorder; 2. attention-deficit/hyperactivity disorder; and 3. autism spectrum disorder. The global functioning mean score of the participants was between 29 and 59 out of 100 through the worst and the best situations of the psychiatric condition.

Discussion: The study findings highlight the predominance of mood disorders and their complications among this group of inpatients as well as their required and special assessments and interventions. Future annual reports can help with better understanding the trends in mental health issues that potentially aids in policymaking and developing treatment guidelines. 


\section{Highlights}

- Over $80 \%$ of the patients admitted to the Child and Adolescent Psychiatry Ward in a 5-year study were diagnosed with bipolar disorder.

- The most common comorbid conditions were attention-deficit/hyperactivity disorder and autism spectrum disorder.

- Over $50 \%$ were suffering from the negative consequences of poor relationships with primary caregivers, academic problems, and social relatedness.

- One-third of the participants at the time of admission functioned poorly, a low functioning situation which usually exists before the emergences of the full-blown syndrome.

\section{Plain Language Summary}

This 5-year study provides information about common psychiatric disorders in Iranian children and adolescents. Bipolar disorder (a mood disorder) was reported to be the most common disease followed by attention deficit-hyperactivity disorder and autism spectrum disorder. Over half of the children and adolescents admitted to hospital suffering from a poor relationship with parents and other caregivers as well as academic issues and impaired social relationships. Most of them functioned poorly due to psychiatric disorders and needed comprehensive rehabilitation strategies.

\section{Introduction}

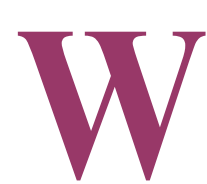

orldwide reports on the prevalence of psychiatric disorders in children and adolescents range from $(3 \%)$ to $(22.5 \%)$ with a median of (12\%) for serious emotional disturbances [1-3]

The most common diagnoses in nonclinical settings are reported to be anxiety and disruptive behavior disorders [2]. Based on a recent survey in Australia, the number of the youth with serious mental illnesses has been on the rise from (18.7\%) in 2012 to $(22.8 \%)$ in 2016, with depression is among the top three reported problems [4]. Investigating 10123 adolescents, the National Comorbidity Survey Adolescent Supplement (NCS-A) found that anxiety disorders $(31.9 \%)$, behavioral disorders (19.1\%), mood disorders (14.3\%), and Substance Use Disorders (SUD) (11.4\%) constitute the most common psychiatric problems in the youth [4].

From 3042 participants aged 8 to 15 years, AttentionDeficit/ Hyperactivity Disorder (ADHD), mood disorders, Conduct Disorder (CD), panic disorder or Generalized Anxiety Disorder (GAD), and eating disorders (ED) were reported in $(8.6 \%),(3.7 \%),(2.1 \%),(7.1 \%)$, and $(0.1 \%)$, respectively [5]. Another American study in eight psychiatric hospitals reported that mood disorders were more common than other disorders among children and adolescents (38\%) [6]. In a Nigerian tertiary aca- demic psychiatric hospital, $50 \%$ of the referrals suffered from schizophrenia [7]. In a group of inpatients in Taiwan, the first three common diagnoses were depressive disorder (50\%), Bipolar Disorder (BD) (14.3\%), and schizophrenia (14.3\%) [8]. Hoare et al. (1996) reported that (37\%) of all new referrals to Scotland outpatient centers had conduct and mixed disorders.

Several community-based studies have investigated the prevalence of childhood psychiatric problems in Iran. The overall frequency of psychological disorders in a sample of 6-11 year-old children in the suburbs of Tehran was $(17.9 \%)$, among whom the most common problems were reported ADHD (8.6\%), Oppositional Defiant Disorder (ODD) (7.3\%), and Separation Anxiety Disorder (SAD) (5.9\%) [9]. Another study on over a 1000 adolescent boys and girls (12-17 years) reported ADHD, ODD, depressive disorders, and SAD as the most prevalent disorders [9]. A national study in five provinces of Iran found ODD (4.45\%) as the most and substance use disorder $(0 \%)$ as the least prevalent psychiatric problems in children and adolescents. ADHD was more common in boys $(5.3 \%)$ with the age range of 6-9 years, while ODD was more diagnosed in girls (4-50\%) with the age range of $10-18$ years [9].

Various measurement scales have been implemented in Iran to assess the status of psychiatric disorders in the youth. Studies on the validity of the Child Behavior Checklist(CBCL) and the Strengths andDifficulties Ques- 
tionnaire (SDQ) in 141 children and adolescents referring to an outpatient hospital clinic in Tehran found that all subscale scores were higher than community samples $[9,10]$. Based on the reported cut-off points for SDQ, the prevalence of the emotional and behavioral problems in a community sample of 7-11 year-old Iranian students $(n=600)$ was $(16.08 \%)$. In total, $(8.75 \%)$ of the girls and $(10.4 \%)$ of the boys had psychiatric problems while being assessed with the CBCL and the Teacher Report Form (TRF) [10]. The assessment of the psychometric properties of the validated Persian version of the Kiddie Schedule for Affective Disorders and Schizophrenia (KSADS) [11] in an inpatient setting indicates that the most common diagnoses were BD (80.4\%), ADHD (34.3\%), and psychotic disorders (27.5\%) [11].

Despite the existing evidence, no long-term studies on inpatient admissions of Iranian children and adolescents have been carried out so far to present a clinical and demographic picture of the current status of psychiatric disorders among them. As a result of this, we aimed at evaluating these features in a child and adolescent ward at a referral psychiatric hospital. An additional objective was to set a registration system to evaluate the inpatient clinical diagnoses and symptoms and their associated epidemiological characteristics.

\section{Methods}

\section{Study design \& setting}

In a 5-year prospective observational study, we recruited all children and adolescents admitted to the Roozbeh Hospital, an academic psychiatric center in Tehran, Iran. Affiliated with Tehran University of Medical Sciences, Roozbeh Hospital is a major referral center with over 30000 annual outpatient visits and over 2000 admissions.

\section{Study Measures}

To gather the required data, routine clinical and paraclinical evaluations, including clinical interview and history taking, as well as appropriate psychological tests, were initially performed. Two semi-structured questionnaires addressing important demographic and clinical characteristics were also used by psychiatry residents and further checked by child and adolescent psychiatry fellowships. All completed questionnaires were, then, rechecked by an assistant professor of child and adolescents psychiatry. Psychiatric diagnoses were made based on the multi-axial (DSM-IV TR) classification. If there was any missing or incorrect data, the questionnaire would be referred back to the responsible resident to be completed or corrected.

The utilized measure are as follow: 1. Roozbeh Hospital Item Sheet: To detect the clinical and demographic characteristics of the participants, we designed a questionnaire. This item sheet includes a summary of the major aspects of diagnosis, symptoms, and treatment to select the cases for research purposes and to review the performance of the department; 2. Children's Global Assessment Scale: Children's Global Assessment Scale (CGAS) is an adaptation of the Adult Global Assessment Scale (GAS), which was developed to be a child-specific measure of functioning [12]. The measure is currently used in diagnosis, treatment, and evaluation of children's mental health problems. The different areas of social and psychological functioning are scored from 0 (the lowest level) to 100 (the highest level of function). Previous studies suggest high reliability ranging from $(0.83)$ to $(0.91)$ with moderate inter-rater reliability in clinical settings [13]. The face validity of the Persian version of the measure has been proved in other studies [14].

\section{Statistical analysis}

The data were entered into standard sheets provided in the Statistical Package for Social Sciences SPSS V. 16 For descriptive variables, we utilized percentage and frequency. Chi-square analysis was used to compare categorical variables, and t test was performed, where means had to be compared. We applied the Analysis of Variance (ANOVA) and linear regression analysis to find the correlation between parametric variables and the relationship between the data and the age, respectively.

\section{Results}

From October 2004 to June 2009, 192 children and adolescents, who were admitted for the first time, participated in the study. Their mean age was 15.2 years $(\mathrm{SD}=2.36$; range: $5-20),(55.8 \%)$ of whom were boys. A few preschoolers and some individuals older than 18 years had been admitted because of their specific needs (e.g. short stature, low mental age, and being at risk of violence or abuse). The mean period of admission was 40.12 ( $\mathrm{SD}=16.15$ ) days (range: $1-112$ days).

The frequency of Axis I psychiatric disorders based on the five axes system is summarized in (Table 1). The most prevalent disorders were BD, ADHD, and ASD. The occurrence of comorbid conditions with BD has been summarized in (Table 2). Only nine patients were 11 years or younger; five were diagnosed with BD 
Table 1. The frequency and percentage of Axis I psychiatric disorders $(n=192)$

\begin{tabular}{|c|c|c|c|}
\hline \multicolumn{2}{|c|}{ Type } & \multirow{2}{*}{$\begin{array}{c}\text { Frequency } \\
160\end{array}$} & \multirow{2}{*}{$\begin{array}{r}\text { Percent } \\
83.3\end{array}$} \\
\hline & Bipolar disorder & & \\
\hline & ADHD & 34 & 17.7 \\
\hline & ASD & 33 & 17.2 \\
\hline \multirow[t]{9}{*}{ Psychiatric disorder } & OCD & 14 & 7.3 \\
\hline & Conduct disorder & 12 & 6.3 \\
\hline & MDD & 9 & 4.7 \\
\hline & ODD & 6 & 3.1 \\
\hline & Schizophrenia & 6 & 3.1 \\
\hline & Tic Disorder & 4 & 2.1 \\
\hline & Unknown & 4 & 2.1 \\
\hline & Somatoform disorder & 2 & 1 \\
\hline & & & \\
\hline \multirow{4}{*}{ Disorder } & Panic disorder & 1 & 0.5 \\
\hline & Schizoaffective disorder & 1 & 0.5 \\
\hline & Trichotillomania & 1 & 0.5 \\
\hline & Anorexia nervosa & 1 & 0.5 \\
\hline
\end{tabular}

ADHD: Attention Deficit Hyperactivity Disorder; ASD: Autism Spectrum Disorder; ${ }^{* *}$ MDD: Major Depressive Disorder; ODD: Oppositional Defiant Disorder

Table 2. Comorbidities in the participants with bipolar disorders $(n=160)$

\begin{tabular}{cccc}
\hline Type of Disorder & No. & Percent \\
\hline ADHD & 32 & 20 \\
\hline ASD & 28 & 17.5 \\
\hline Conduct disorder & 11 & 6.8 \\
\hline OCD & 9 & 5.6 \\
\hline ODD & 5 & 3.1 \\
\hline Tourette syndrome & 3 & 1.2 \\
\hline Learning disability & 2 & 0.6 \\
\hline Trichotillomania & 1 & 0.6 \\
\hline Somatoform disorder & 1 & 0.6 \\
\hline
\end{tabular}

ADHD: Attention Deficit Hyperactivity Disorder; ASD: Autism Spectrum Disorder; OCD: Obsessive-Compulsive Disorder; ODD: Oppositional Defiant Disorder 
Table 3. Frequency and percentage of psychosocial problems

\begin{tabular}{|ccc|}
\hline Psychosocial Factors & No. & Percent \\
\hline Relationship with primary caregiver & 113 & 58.9 \\
Social relationships & 98 & 51 \\
Academic level & 113 & 58.9 \\
\hline Occupational status & 7 & 3.6 \\
\hline Residence & 30 & 15.6 \\
\hline Economic situation & 65 & 33.9 \\
\hline Access to urban services & 13 & 6.8 \\
\hline Legal issues & 11 & 5.7 \\
Others & 23 & 12 \\
\hline
\end{tabular}

Iranian Rehabilitation Journal

Table 4. Prevalence of emotional symptoms among participants ( $\mathrm{n}=192)$

\begin{tabular}{|c|c|c|c|c|}
\hline \multirow{3}{*}{$\begin{array}{c}\text { Emotional Symptoms } \\
\text { Abnormal suspiciousness or 'sensitivity' }\end{array}$} & \multicolumn{4}{|c|}{ No. \% } \\
\hline & \multicolumn{2}{|c|}{ Dubious or Minimal } & \multicolumn{2}{|c|}{ Definitely Present } \\
\hline & 44 & 23.3 & 55 & 29.1 \\
\hline Morbid anxiety, worrying, or panic & 57 & 30.2 & 55 & 29.1 \\
\hline Phobia & 29 & 15.3 & 14 & 7.4 \\
\hline Morbid depression, sadness, unhappiness, and tearfulness & 57 & 30.2 & 64 & 33.9 \\
\hline $\begin{array}{c}\text { Guilt, self-blame, ideas of hopelessness, and other depressive-type cogni- } \\
\text { tions }\end{array}$ & 44 & 23.3 & 30 & 19.9 \\
\hline Situation or object-specific fears or phobias & 22 & 11.6 & 15 & 7.9 \\
\hline $\begin{array}{r}\text { Ruminations, obsessions, rituals or compulsions (not faddiness, rigidity, or } \\
\text { other obsessive traits) }\end{array}$ & 25 & 13.2 & 35 & 18.5 \\
\hline Suicidal ideas or threats & 33 & 17.5 & 47 & 24.9 \\
\hline Suicidal attempts & 15 & 7.9 & 29 & 15.3 \\
\hline Hypochondriasis & 6 & 3.2 & 11 & 5.9 \\
\hline Morbid irritability, screaming, tempers, and breath-holding attacks & 22 & 11.6 & 148 & 78.3 \\
\hline School refusal, or phobia or crying on arrival at school & 21 & 11.1 & 19 & 10 \\
\hline Abnormally-elevated mood (including hypomania) & 28 & 14.7 & 123 & 64.7 \\
\hline Depersonalization or derealization & 6 & 3.2 & 4 & 2.1 \\
\hline Conversion hysterical symptoms (not histrionic behavior) & 9 & 4.7 & 2 & 1.1 \\
\hline Intrusive thoughts & 21 & 11.1 & 18 & 9.5 \\
\hline Separation anxiety & 20 & 10.5 & 10 & 5.3 \\
\hline Social anxiety & 26 & 13.7 & 10 & 5.3 \\
\hline
\end{tabular}


Table 5. Comparison of frequency and percentage of psychiatric disorders based on gender

\begin{tabular}{|c|c|c|c|c|c|}
\hline \multirow{3}{*}{$\begin{array}{c}\text { Disorder } \\
\text { Bipolar disorder }\end{array}$} & \multicolumn{4}{|c|}{ No. $\%$} & \multirow{3}{*}{$\begin{array}{c}\mathbf{P} \\
0.64\end{array}$} \\
\hline & \multicolumn{2}{|c|}{ Female } & \multicolumn{2}{|c|}{ Male } & \\
\hline & 72 & 85.7 & 88 & 82.2 & \\
\hline MDD & 5 & 5.9 & 4 & 3.7 & 0.48 \\
\hline OCD & 6 & 7.1 & 8 & 7.5 & 0.91 \\
\hline ADHD & 10 & 11.8 & 24 & 22.4 & $0.05 *$ \\
\hline ODD & 2 & 2.4 & 4 & 3.7 & 0.58 \\
\hline ASD & 9 & 10.6 & 24 & 22.4 & $0.03 *$ \\
\hline Conduct disorder & 5 & 5.9 & 7 & 6.5 & 0.85 \\
\hline Schizophrenia & 2 & 2.4 & 4 & 3.7 & 0.58 \\
\hline Tic disorder & 2 & 2.4 & 2 & 1.9 & 0.81 \\
\hline Learning disability & 2 & 2.4 & 0 & 0 & 0.11 \\
\hline Panic disorder & 0 & 0 & 1 & 0.9 & 0.37 \\
\hline Schizoaffective disorder & 0 & 0 & 1 & 0.9 & 0.37 \\
\hline Trichotillomania & 1 & 1.2 & 0 & 0 & 0.26 \\
\hline Somatoform disorder & 2 & 2.4 & 0 & 0 & 0.11 \\
\hline Anorexia nervosa & 1 & 1.2 & 0 & 0 & 0.26 \\
\hline Unknown & 1 & 1.2 & 2 & 1.9 & 0.70 \\
\hline
\end{tabular}

Iranian Rehabilitation Journal

ADHD: Attention Deficit Hyperactivity Disorder; ASD: Autism Spectrum Disorder; OCD: Obsessive-Compulsive Disorder; ODD: Oppositional Defiant Disorder

$*<0.05 ; * * 0.01$

(three with comorbid ADHD); three had ASD, and one had no definitive diagnosis. This age group is not considered in the following tables.

The most prevalent comorbid conditions were ADHD, $\mathrm{CD}$, and ODD $(\mathrm{n}=9)$. Eleven patients with $\mathrm{BD}$ had at least two other comorbid disorders. Two had three concurrent disorders: OCD+ADHD+Asperger, and OCD + Tourette syndrome+Asperger syndrome. Among the participants with any psychiatric disorders other than $\mathrm{BD}$, the highest comorbidities were Major Depressive Disorder (MDD) with $\operatorname{OCD}(n=3)$. From all patients diagnosed with BD, 16 had psychotic features, while 13 were female.

Regarding the Axis II diagnosis based on clinical psychiatric judgment, 25(13\%) patients had mild mental disability (borderline IQ in eight). Personality traits were reported in five (histrionic $(\mathrm{n}=2)$, borderline $(\mathrm{n}=2)$, and narcissistic features $(n=1))$. The most common medical conditions included convulsions $(n=8)$, encephalitis $(n=1)$, head trauma $(n=2)$, cerebral palsy $(n=1)$, and brain tumor $(\mathrm{n}=1)$.

In terms of psychosocial situations, over (50\%) suffered from the negative consequences of poor relationships with primary caregivers, academic problems, and social relatedness (Table 3).

\section{The Children's Global Assessment Scale}

The Mean \pm SD participants' Children's Global Assessment Scale (CGAS) score was $41.36 \pm 15.64$ at the time of evaluation, $28.95 \pm 9.32$ in the worst situation in the 
past (before admission), and $59.62 \pm 16.6$ in the best situation in the past (before admission).

Table 4 presents the prevalence of emotional symptoms in our sample. Of 47 patients with definite suicidal ideation, 37 were diagnosed with $\mathrm{BD}$, three with MDD, and 7 with schizophrenia; comorbidity with ADHD, ODD, and $C D$ were observed in 22 patients. A suicidal attempt was reported in 29 , of whom 23 were diagnosed with BD, 2 with MDD, and 1 with schizophrenia. Likewise, 14 patients had comorbid conditions, including ADHD, ODD, and CD.

The participants of this study had difficulties in their relationship with parents $(63.3 \%)$, peers $(31.1 \%)$, other adults $(29.6 \%)$, their siblings $(27.9 \%)$, and social interactions $(24.2 \%)$. The most common language problems were disorders of production of spoken language $(8.9 \%)$, impaired use of language for social communication $(8.9 \%)$, and disorders of articulation $(6.8 \%)$. The prevalence of motor problems was high in terms of gross overactivity $(52.1 \%)$, restlessness/ fidgetiness (36.8\%), and motor habits such as thumb sucking, rocking, and nail-biting (12.6\%). Among disruptive or conduct behaviors, the most prevalent symptoms were temper outbursts $(55.8 \%)$, defiance $(44.71 \%)$, arguing with adults (44.4\%), anger (42.6\%), resentment (41.6\%), and others such as fighting, bullying, and aggression (40.5\%).

Impaired concentration and markedly impulsive behavior were among the other prevalent symptoms reported in (49.5\%) and (46.2\%), respectively, while hallucinations and delusions were detected in only (22.6\%). Besides, (17.7\%) of the patients showed self-injurious behavior. Among other important factors evaluated through the questionnaire, the history of physical abuse in the last year was found in $(9 \%)(6.9 \%$ for sexual abuse). The lifetime prevalence of physical and sexual abuse were $(6.9 \%)$ and $(6.4 \%)$, respectively. (Table 5) compares the frequency and percentage of psychiatric disorders with the gender groups. Based on the results of the linear regression analysis, there were no significant correlations between the participants' age and duration of hospitalization or their overall functioning.

\section{Discussion}

We aimed at registering the clinical and demographic characteristics of children and adolescents admitted to a major referral center in a 5-year period to establish a data registry and to update experts in the field of the trend of psychiatric disorders.
The most prevalent disorder among the study participants was BD. This finding is consistent with the findings of studies performed in Europe and North America. Based on the records of the annual National Hospital Discharge Survey in the United States, the populationadjusted rates of hospital discharge of children with a primary diagnosis of BD increased from 1.3 per 10000 American children in 1996 to 7.3 per 10000 in 2004 and remained stable until $2006[15,16]$. In a nation-wide study in Denmark, the annual rates of BD had two to four-fold increase from 1995 to 2012 [15].

It is not evident whether this increase is related to greater attention to mood dysregulation in this age group or changes in criteria for admission. Scott et al. (2000) found a significant variation in proportions of children with externalizing, internalizing, or caregiver problems and their severity between hospitals; nevertheless, the most common disorders were primary mood disorder (38\%), ADHD and disruptive behavior disorders (18\%), and anxiety disorders (16\%) [17]. However, contradicting findings are reported in other parts of the world. In Nigeria, $(50 \%)$ of the referrals to a tertiary academic center had schizophrenia, (15\%) had delirium, and $9 \%$ had seizure disorders [7]. Nevertheless, they mentioned that the proportion of mood and psychotic disorders to other diagnoses increased in time along with the changes in diagnostic and classification systems and promotion in professionals' knowledge and attitude toward childhood psychiatric problems.

Although ASD and ADHD were the next most common disorders in our ward, they were not considered the main reasons for admission. Only (3\%) of the patients had some kinds of non-affective psychotic disorders; however, the ratings of psychotic symptoms were one-tenth in participants with BD. According to the literature, $\mathrm{ADHD}, \mathrm{CD}$, and anxiety disorder are known as the most common comorbid conditions with $\mathrm{BD}$ [18, 19]. In our study, ADHD, ASD, CD, and OCD were the most prevalent comorbid conditions, in that order. An unexpected finding was the small number of youth with anxiety disorders.

A probable explanation is that the prominent symptoms of mood liability may have covered minor anxious symptoms. Overall, comorbidities were highly reported, a fact that underscores the importance of thorough assessment of addressing various symptoms. Also of note, the higher number of girls with psychotic features compared with boys suggests considering cultural factors, which need to be further investigated. 
Although EDs are a discernible reason for referral of adolescents to psychiatric wards in many countries, it was reported by only one participant in this study [20]. It is not obvious whether the difference is related to the real low prevalence of ED in our community or the low level of their referrals to psychiatric centers. The other probable explanation includes limited public awareness about eating problems, different cultural aspects or attitudes towards body image, or different biological factors.

The most common emotional symptoms among the study participants were irritability and temper tantrum $(78.3 \%)$ as well as pathological-elevated mood (e.g. hypomania $(64.7 \%))$. This finding is consistent with the results of a meta-analysis, showing that the most common symptom in manic children was irritability [21]. Although irritability is more common in children with BD compared to adults, it is not a specific symptom for mania because it is reported in a broad range of childhood psychiatric disorders such as psychosis, ADHD, ASD, and CD [22]. Therefore, we may also attribute this symptom to the high prevalence of ADHD and ASD in our participants

One-fourth of the participants had suicidal ideas or threats, and $(15.3 \%)$ of them had attempted suicide. In the United States, $(15 \%)$ of the deaths in adolescents in the age range of 15 to 19 were caused by suicide [23]. Generally, (90\%) of the children and adolescents, who died from suicide and $(6 \%)$ of those who attempted suicide, have major psychopathology, $(60 \%)$ to $(80 \%)$ of which are related to depressive and bipolar mood disorders [24]. Other disorders increase the risk of suicide, such as disruptive behavior disorders, which were common in our study as well [25]. More than half of the participants reported relational, social, and economic problems, which may lead to feelings of frustration and low self-esteem. These factors may end up in relapse or chronicity of symptoms or suicidal ideation or attempt.

And finally, the level of the general functioning of the participants was low even before the beginning of psychiatric problems. This level was much lower at the time of admission and improved partially on discharge. These facts underscore the importance of rehabilitation strategies for youth with psychiatric disorders, especially those who are diagnosed with major disorders and severe enough to be admitted for a rather long time.

These youths are far from school and academic learning for a significant time during the admission and are not ready enough to return to school soon after discharge. The mental and social adaptation of these children and adolescents need professional and psychosocial help. Day centers are helpful with providing special rehabilitation programs such as occupational therapy, group therapy, psychotherapy, specia teachers for the patients, and psychoeducational programs for families to help their children adjust with the condition.

\section{Conclusions}

Bipolar mood disorder was the most common diagnosis in this 5-year study performed at a referral child and adolescent center. Irritability and temper tantrums were among the most common emotional symptoms at the time of admission; over (15\%)of the patients had suicidal ideation. We suggest a discharge plan to be set for all children and adolescents based on the current findings. This will cover their need to be followed for a longer period after discharge and help evaluate the diagnostic stability and outcome. We can reach this goal easier when we implement the registration process throughout the hospital, using a more comprehensive computerized system.

\section{Ethical Considerations}

\section{Compliance with ethical guidelines}

All procedures were in compliance with the 1975 Declaration of Helsinki. Written consents and oral ascents were obtained from parents and children, respectively (wherever applicable). No identifying information was documented.

Funding

The current study proposal was approved and supported by the Institutional Review Board of the Tehran University of Medical Sciences (Grant No. 89-02-30-10812).

\section{Authors' contributions}

Conceptualization, formal analysis: Mehdi TehraniDoost; Methodology, Software: Mehdi Tehrani-Doost, Zahra Shahrivar; Investigation, writing-original draft, Supervision, project administration, funding: Zahra Shahrivar; Writing-review and editing: Rosa Alikhani.

\section{Conflict of interest}

Authors declared no conflict of interest

\section{Acknowledgments}

The researchers are grateful for the exceptional contribution of all psychiatry residents and child and adolescent fellowships, who completed the assessments of the project. 


\section{References}

[1] Brandenburg NA, Friedman RM, Silver SE. The epidemiology of childhood psychiatric disorders: Prevalence findings from recent studies. Journal of the American Academy of Child \& Adolescent Psychiatry. 1990; 29(1):76-83. [DOI: 10.1097/00004583-199001000-00013] [PMID]

[2] Belfer ML. Child and adolescent mental disorders: The magnitude of the problem across the globe. Journal of Child Psychology and Psychiatry, and Allied Disciplines. 2008; 49(3):226-36. [DOI:10.1111/j.1469-7610.2007.01855.x] [PMID]

[3] Costello EJ, Foley DL, Angold A. 10-year research update review: The epidemiology of child and adolescent psychiatric disorders: II. Developmental epidemiology. Journal of the American Academy of Child and Adolescent Psychiatry. 2006; 45(1):8-25. [DOI:10.1097/01.chi.0000184929.41423.c0] [PMID]

[4] Mission Australia. Youth mental health report: youth survey 2012-16. Australian Indigenous Health Bulletin. 2017; 17(2).

[5] Merikangas KR, He JP, Brody D, Fisher PW, Bourdon K, Koretz DS. Prevalence and treatment of mental disorders among US children in the 2001-2004 NHANES. Pediatrics. 2010; 125(1):75-81. [DOI:10.1542/peds.2008-2598] [PMID] [PMCID]

[6] Leon SC, Lyons JS, Uziel-Miller ND. Variations in the clinical presentations of children and adolescents at eight psychiatric hospitals. Psychiatric Services. 2000; 51(6):786-90. [DOI:10.1176/appi.ps.51.6.786] [PMID]

[7] Tunde-Ayinmode M. Audit of child and adolescent psychiatry in a teaching hospital in Nigeria: Prevalence, pattern and implication for improved services. South African Journal of Psychiatry. 2010; 16(1):20-6. [DOI:10.4102/sajpsychiatry. v16i1.209]

[8] Chiou PN, Chen YS, Lee YC. Characteristics of adolescent suicide attempters admitted to an acute psychiatric ward in Taiwan. Journal of the Chinese Medical Association. 2006; 69(9):428-35. [DOI:10.1016/S1726-4901(09)70286-2]

[9] Alavi A, Mohammadi MR, Joshaghani N, MahmoudiGharaei J. Frequency of psychological disorders amongst children in urban areas of Tehran. Iranian Journal of Psychiatry. 2010; 5(2):55-9.

[10] Tehrani-Doost M, Shahrivar Z, Pakbaz B, Rezaie A, Ahmadi F. Normative data and psychometric properties of the child behavior checklist and teacher rating form in an Iranian community sample. Iranian Journal of Pediatrics. 2011; 21(3):331-42. [PMID] [PMCID]

[11] Shahrivar Z, Kousha M, Moallemi S, Tehrani-Doost M, Alaghband-Rad J. The reliability and validity of kiddieschedule for affective disorders and schizophrenia-present and life-time version-Persian version. Child and Adolescent Mental Health. 2010; 15(2):97-102. [DOI:10.1111/j.14753588.2008.00518.x]

[12] Shaffer D, Gould MS, Brasic J, Ambrosini P, Fisher P, Bird H et al. A Children's Global Assessment Scale (CGAS). Archives of General Psychiatry. 1983; 40(11):1228-31. [DOI:10.1001/ archpsyc.1983.01790100074010] [PMID]

[13] Lundh A, Kowalski J, Sundberg CJ, Gumpert C, Landén M. Children's Global Assessment Scale (CGAS) in a naturalistic clinical setting: Inter-rater reliability and comparison with expert ratings. Psychiatry Research. 2010; 177(1):206-10. [DOI:10.1016/j.psychres.2010.02.006] [PMID]

[14] Riahi F, Tashakori A, Izadi-Mazidi S. Effectiveness of reboxetine in treatment of outpatient children and adolescents with attention deficit-hyperactivity disorder with comorbid anxiety disorders. Iranian Journal of Psychiatry. 2013; 8(4):195-200.

[15] Kessing LV, Vradi E, Andersen PK. Are rates of pediatric bipolar disorder increasing? Results from a nationwide register study. International Journal of Bipolar Disorders. 2014; 2(1):10. [DOI:10.1186/s40345-014-0010-0] [PMID] [PMCID]

[16] Lasky T, Krieger A, Elixhauser A, Vitiello B. Children's hospitalizations with a mood disorder diagnosis in general hospitals in the United States 2000-2006. Child and Adolescent Psychiatry and Mental Health. 2011; 5(1):27. [DOI:10.1186/1753-2000-5-27] [PMID] [PMCID]

[17] Scott CL, Lyons JS, Uziel-Miller ND. Variations in the clinical presentations of children and adolescents at eight psychiatric hospitals. Psychiatric Services. 2000; 51(6):786-90. [DOI:10.1176/appi.ps.51.6.786] [PMID]

[18] Pavuluri MN, Birmaher B, Naylor MW. Pediatric bipolar disorder: A review of the past 10 years. Journal of the American Academy of Child \& Adolescent Psychiatry. 2005; 44(9):846-71. [DOI:10.1097/01.chi.0000170554.23422.c1] [PMID]

[19] Tillman R, Geller B, Bolhofner K, Craney JL, Williams M, Zimerman B. Ages of onset and rates of syndromal and subsyndromal comorbid DSM-IV diagnoses in a prepubertal and early adolescent bipolar disorder phenotype. Journal of the American Academy of Child \& Adolescent Psychiatry. 2003, 42(12):1486-93. [DOI:10.1097/00004583-200312000-00016] [PMID]

[20] Striegel-Moore RH, Franko DL. Epidemiology of binge eating disorder. International Journal of Eating Disorders. 2003; 34(S1):S19-29. [DOI:10.1002/eat.10202] [PMID]

[21] Kowatch RA, Fristad M, Birmaher B, Wagner KD, Findling RL, Hellander M. Treatment guidelines for children and adolescents with bipolar disorder. Journal of the American Academy of Child \& Adolescent Psychiatry. 2005; 44(3):21335. [DOI:10.1097/00004583-200503000-00006]

[22] Carlson GA, Bromet EJ, Driessens C, Mojtabai R, Schwartz JE. Age at onset, childhood psychopathology, and 2-year outcome in psychotic bipolar disorder. American Journal of Psychiatry. 2002; 159(2):307-9. [DOI:10.1176/appi.ajp.159.2.307] [PMID]

[23] Kennebeck S, Bonin L. Suicidal behavior in children and adolescents: Epidemiology and risk factors [Internet]. 2015 [Updated 2017 July 8]. Available from: https://www.uptodate.com/contents/suicidal-behavior-in-children-and-adolescents-epidemiology-and-risk-factors\#H2670495.

[24] Brent DA, Perper JA, Moritz G, Liotus L, Schweers J, Balach L, et al. Familial risk factors for adolescent suicide: A case-control study. Acta Psychiatrica Scandinavica. 1994; 89(1):52-8. [DOI:10.1111/j.1600-0447.1994.tb01485.x] [PMID]

[25] Milton J, Ferguson B, Mills T. Risk assessment and suicide prevention in primary care. Crisis. 1999; 20(4):171-7. [DOI 10.1027//0227-5910.20.4.171] [PMID] 
This Page Intentionally Left Blank 